\title{
]jfis
}

\section{A Theoretical Approach of Astronomical Ship Positioning Using a Single Celestial Body and Secant Technique}

Van Suong Nguyen

Faculty of Navigation, Vietnam Maritime University, 484 Lachtray Str., Hai Phong City, Vietnam
Received: Jan. 16, 2020

Revised : Feb. 17, 2020

Accepted: Feb. 28, 2020

Correspondence to: Van Suong Nguyen (nguyenvansuong@vimaru.edu.vn) (CThe Korean Institute of Intelligent Systems

cCThis is an Open Access article distributed under the terms of the Creative Commons Attribution Non-Commercial License (http://creativecommons.org/licenses/ by-nc/3.0// which permits unrestricted noncommercial use, distribution, and reproduction in any medium, provided the original work is properly cited.

\begin{abstract}
In this article, a new approach to solve an astronomical ship position is proposed based on a single celestial body and secant technique. The mathematical equations relating the ship position to a celestial body are described using an altitude and an azimuth of celestial body. These equations are established using knowledge of spherical trigonometry. Numerical analysis is then employed based on secant method to solve the mathematical equations for the ship position. This technique uses the altitude and the azimuth simultaneously while existing methods need to observe the altitude either of two celestial bodies or of a single body at two different times. Therefore, it is worth to apply this proposed technique when there is only a single celestial body identified. To validate the feasibility of the proposed technique, two numerical examples were performed.
\end{abstract}

Keywords: Celestial navigation, Astronomical ship positioning, Single body, Secant method, Numerical method

\section{Introduction}

The fixing of ship position at sea is an important task of navigation officers to keep the ship on her desired route. To date, global positioning system (GPS) has proven their capacity in determining the ship position precisely, quickly, and continuously. However, the signal received from GPS satellites is sometimes impossible because of solar flares, magnetic storms or other reasons, and thus the GPS receivers cannot operate in these situations. To overcome the drawbacks of GPS system in such unavailable cases, the traditional navigation method such as celestial navigation technique may be used. Intercept method has been known as most popular technique of celestial navigation to find out the ship position. To handle this method, the altitude of celestial bodies and an assumed position must be determined to establish the parameters of the line of position equation (LOP), the equations for positioning are then solved by calculation program or graphic plotting. Actually, the ship position is an intersection of circles of an equal altitude (COP) instead of LOP. Recently, with the rapid development of computer science, new computing methods have been proposed to solve the COP equations specifically for the ship position. In research of the authors [1] the trigonometric expanding technique was described to solve directly the COP equations. Later on, in [2], the vector calculus was introduced to obtain the COP equation with three unknowns in the Cartesian coordinate system, and the technique of vector expansion was then suggested to solve the ship position. 
By using the evolution algorithms in artificial intelligence, studies referred in [3, 4] applied the genetic algorithm and the particle swarm optimization to determine an optimal position of ship. The advantage of these optimal algorithms is to imitate the natural processes of biological evolution in searching the global solution for complex problems without certain equations. As a continuation of the work based on the vector calculus, the authors in [5] suggested the singular value decomposition (SVD) technique integrated the least square method which is more stable than the normal method. Recently, a stand-alone celestial navigation positioning method was presented by [6]. In this study, the fixing problem was investigated for both stationary and moving observers. The advantage of this method is simplicity of the mathematical theory and applicable to portable devices. For obtaining the ship position when the horizon is invisible, the research [7] proposed an azimuth method based on the governing equations between the ship position and the great-circle azimuth of the celestial bodies. Meanwhile, the study [8] used the positioning equations through the spherical trigonometry. To improve the applicable ability of the azimuth method, a method combining the azimuth of celestial body with factors of ship route was investigated in [9].

Although the above-mentioned researches have significantly contributed to the celestial navigation for fixing, there have been still unsolved problems of fixing a position. For example, it is required to measure the altitude or azimuth of either at least two celestial bodies or a single celestial body at two different times. Besides, the existing methods of celestial navigation with more than two celestial bodies require time-consuming to conduct because many steps need to be done before fixing.

In this research, a new approach to obtain astronomical ship position is studied based on a single celestial body and secant method. The mathematical equations relating the ship position to celestial body are described based on an altitude and an azimuth of celestial body. These equations are established using knowledge of spherical trigonometry. Numerical method based on secant technique is then employed to solve the mathematical equations for ship position. The main contributions of this investigation are as follows:

First, our proposed method can perform with a single celestial body at a given time. Instead of more than two celestial bodies, this method requires only a single body. Therefore, it can be useful for some cases where there is only an identified single celestial body.

Secondly, applying secant technique to solve the system is seen as one of new approaches of advanced mathematics in
Table 1. Variables and symbols

\begin{tabular}{ccc}
\hline Symbol & Variable & Interval \\
\hline$G H A$ & $\begin{array}{c}\text { Greenwich hour } \\
\text { angle }\end{array}$ & $0 \leq G H A \leq 360^{\circ}(\mathrm{W}$ to E) \\
$L H A$ & Local hour angle & $0 \leq L H A \leq 360^{\circ}(\mathrm{W}$ to E) \\
$\delta$ & Declination & $-90^{\circ}(\mathrm{S}) \leq \delta \leq+90^{\circ}(\mathrm{N})$ \\
$\varphi$ & Latitude & $-90^{\circ}(\mathrm{S}) \leq \varphi \leq+90^{\circ}(\mathrm{N})$ \\
$\lambda$ & Longitude & $-180^{\circ}(\mathrm{W}) \leq \lambda \leq+180^{\circ}(\mathrm{E})$ \\
$A$ & $\begin{array}{c}\text { Azimuth of } \\
\text { celestial body }\end{array}$ & $0 \leq A \leq 360^{\circ}$ \\
$H$ & $\begin{array}{c}\text { Altitude of } \\
\text { celestial body }\end{array}$ & $0 \leq H \leq 90^{\circ}$ \\
\hline
\end{tabular}

celestial navigation. This technique can be a useful reference for navigators and marine students.

To verify the effectiveness of the proposed technique, two numerical examples were performed. The results showed that this technique has good performance for finding the ship position. This article consists of the parts as follows: mathematical equations for ship position are presented in Section 2. The detail of the proposed technique is shown in Section 3. Results of numerical examples are described in Section 4. The conclusion is summarized in Section 5 .

\section{Mathematical Equations for Ship Position}

\subsection{The Relation of the Ship Position and Celestial Body}

Before establishing the governing mathematical equations for ship position, it is necessary to describe the parameters on a celestial sphere. Additionally, variables and symbols also are interpreted in this section. The Earth is considered as a perfect sphere. The ship position $(P)$, a celestial body $(C)$ and the factors of the Earth such as the meridians, the circles of latitude, and the equator are projected on a virtual sphere that is called as celestial sphere shown as Figure 1. On this celestial sphere, the ship position is defined by latitude $(\varphi)$ and longitude $(\lambda)$, and the celestial body is denoted by Greenwich hour angle (GHA) and Declination $(\delta)$. The details of variables and symbols are represented as in Table 1. From Figure 2, the relation of longitude and hour angles is presented as follows:

$$
\begin{aligned}
& L H A^{\text {East }}=G H A^{\text {East }}+\lambda^{\text {East }}, \\
& L H A^{\text {West }}=G H A^{\text {West }}-\lambda^{\text {West }} .
\end{aligned}
$$

Generally, Eq. (1) and Eq. (2) can be rewritten concisely in 


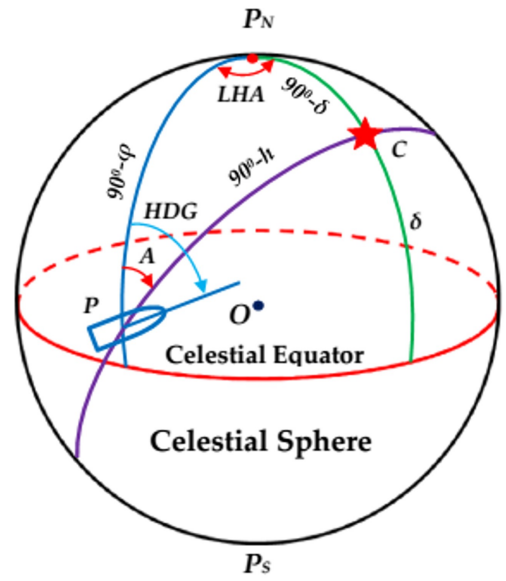

Figure 1. The relation between the ship position and celestial body on celestial sphere.

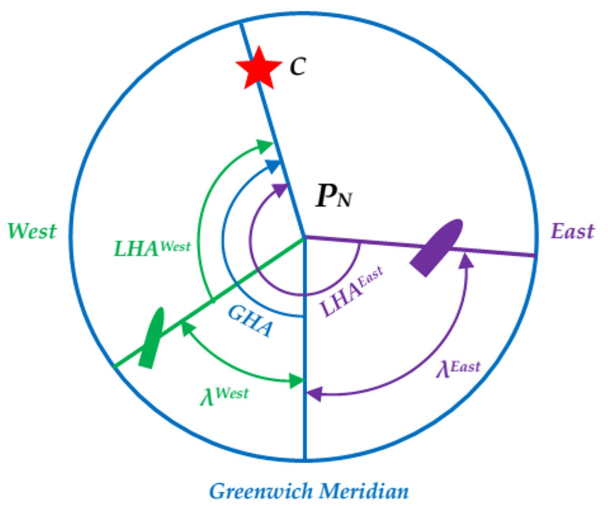

Figure 2. The relation between longitude and hour angles.

the following form

$$
L H A=G H A \pm \lambda_{W e s t}^{\text {East }} \text {. }
$$

$L H A$ in Eq. (3) is defined as the anticlockwise angle from the observer meridian to the celestial body meridian. In fact, $L H A$ can be an arbitrary, and the following rules should be applied in computing process.

If $L H A$ is more than $180^{\circ}$, then this value should be ( $L H A-$ $180^{\circ}$ ). If LHA is more than $360^{\circ}$, then this value should be $\left(L H A-360^{\circ}\right)$. Otherwise, $L H A$ is kept originally in computing process.

\subsection{Mathematical Equations for Ship Position based on the Altitude and the Azimuth}

In this section, the governing formulas are mentioned based on the mathematical laws of spherical triangle to solve the ship position. As illustrated in Figure 3, the spherical triangle $\mathrm{P}_{\mathrm{N}} \mathrm{PC}$

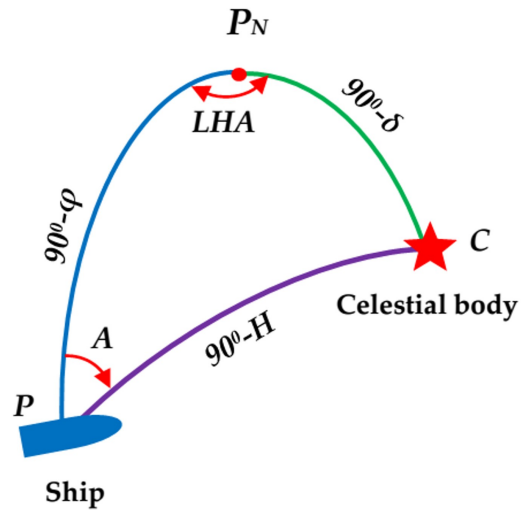

Figure 3. A spherical trigonometry for obtaining the ship position.

is formed by three great-circle arcs: the observer meridian $\left(\mathrm{P}_{\mathrm{N}} \mathrm{P}\right)$, the celestial body meridian $\left(\mathrm{P}_{\mathrm{N}} \mathrm{C}\right)$, and the celestial body-through vertical circle. The detail of using formulas is shown as follows:

Applying the cosine formula of spherical trigonometry to the triangle $\mathrm{P}_{\mathrm{N}} \mathrm{PC}$, we have:

$$
\begin{aligned}
\cos \left(90^{\circ}-H\right)= & \cos \left(90^{\circ}-\varphi\right) \cos \left(90^{\circ}-\delta\right) \\
& +\sin \left(90^{\circ}-\varphi\right) \sin \left(90^{\circ}-\delta\right) \cos (L H A) .
\end{aligned}
$$

Rearranging the above equation, the following equation is obtained

$$
\sin (H)=\sin (\varphi) \sin (\delta)+\cos (\varphi) \cos (\delta) \cos (L H A) .
$$

The four-part law is also employed for the triangle PNPC to have the below formula

$$
\begin{aligned}
\operatorname{cotan}(A) \sin (L H A)= & \operatorname{cotan}\left(90^{\circ}-\delta\right) \sin \left(90^{\circ}-\varphi\right) \\
& -\cos \left(90^{\circ}-\varphi\right) \cos (L H A) .
\end{aligned}
$$

Rewriting the above equation, the following form is yielded $\operatorname{cotan}(A) \sin (L H A)+\sin (\varphi) \cos (L H A)=\tan (\delta) \cos (\varphi)$.

In Section 3, Eq. (5) and Eq. (7) are simultaneously applied to solve the equation system for ship position. 


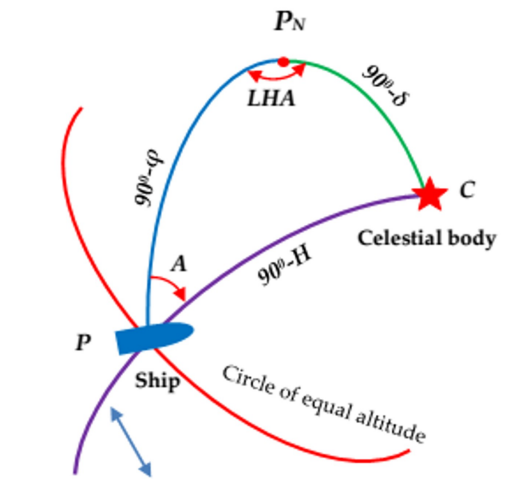

Great circle with observed azimuth at the ship position

Figure 4. A spherical trigonometry for obtaining the ship position.

\section{A New Approach of Astronomical Ship Posi- tioning Based on a Single Celestial Body and Secant Technique}

In this section, the novel technique is represented. Let the ship position $P$ (observer) is at latitude and longitude on the surface of the Earth. At the time $U T C$, the celestial body $(C)$ having the coordinate $(G H A$ and $\delta$ ) is identified and the altitude $(H)$ and the azimuth $(A)$ of this body are measured simultaneously from the position of observer. The ship position is an intersection of two circles which are circle of equal altitude and great circle with observed azimuth at the ship position, as shown in Figure 4 , and the mathematical equations of these circles are applied to solve the ship position. Eq. (5) and Eq. (7) are also employed to solve the ship position.

From Eq. (5), the longitude is expanded to obtain a multivariable function as follows:

$$
\lambda= \pm\left(\operatorname{acos}\left(\frac{\sin (\mathrm{H})-\sin (\varphi) \sin (\delta)}{\cos (\varphi) \cos (\delta)}\right)-\mathrm{GHA}\right) .
$$

Substituting Eq. (8) into Eq. (7), the following equation is yielded

$$
\begin{aligned}
& \operatorname{cotan}(A) \sin \left(\operatorname{acos}\left(\frac{\sin (\mathrm{H})-\sin (\varphi) \sin (\delta)}{\cos (\varphi) \cos (\delta)}\right)\right) \\
& +\sin (\varphi)\left(\frac{\sin (H)-\sin (\varphi) \sin (\delta)}{\cos (\varphi) \cos (\delta)}\right)-\tan (\delta) \cos (\varphi)=0 .
\end{aligned}
$$

Placing function $(F)$ as follows:

$$
F=\operatorname{cotan}(A) \sin \left(\operatorname{acos}\left(\frac{\sin (\mathrm{H})-\sin (\varphi) \sin (\delta)}{\cos (\varphi) \cos (\delta)}\right)\right)
$$

$$
+\sin (\varphi)\left(\frac{\sin (H)-\sin (\varphi) \sin (\delta)}{\cos (\varphi) \cos (\delta)}\right)-\tan (\delta) \cos (\varphi)
$$

The $F$ is a function of latitude $(\varphi)$, and the objective of the problem is how to find out the latitude $(\varphi)$ so that the function $F$ converge to 0 . To deal with this optimization problem, the secant technique in numerical method is employed to conduct the computation procedure. Because Eq. (10) is a simple nonlinear equation with one unknown, and the secant technique is usually efficient to this equation, the secant method is selected for solving Eq. (10) in this paper. The basic form of the solution based on the secant method is presented as follows:

$$
\varphi_{n}=\varphi_{n-1}-F\left(\varphi_{n-1}\right) \frac{\varphi_{n-1}-\varphi_{n-2}}{F\left(\varphi_{n-1}\right)-F\left(\varphi_{n-2}\right)} .
$$

The iterative steps are performed until the difference $\mid \varphi_{n}$ $\varphi_{n-1} \mid$ converges to a desired small value. To solve Eq. (9), two initial values of the latitude $\left(\varphi_{1}, \varphi_{2}\right)$ are initialized as candidate solutions for this equation. These initial values should be close to the true solution; therefore they can be assigned the first latitude and the second latitude as $\varphi_{1}$ and $\left(\varphi_{1} \pm 1^{\circ}\right)$ (depending on the ship's course).

The procedure of computation process of fixing the ship position by single celestial body is conducted as following steps: First step: The ship position $P_{1}\left(\varphi_{1}, \lambda_{1}\right)$ obtained at closest time is recorded. The latitudes $\varphi_{1}$ and $\left(\varphi_{1} \pm 1^{\circ}\right)$ are initialized as two initial solutions for the positioning equation. At the time $U T C$, a celestial body $C$ is identified and selected for fixing.

Second step: The coordinate of the celestial body is also determined at the time $U T C$. The observer (on the ship) measures the altitude $(H)$ and the azimuth $(A)$ of the celestial body.

Third step: Using Eq. (11) is applied to find the solution such that the convergence of the difference $\left|\varphi_{n}-\varphi_{n-1}\right| \leq 0.0001$. The latitude is determined.

Final step: Eq. (8) is employed to obtain the longitude of the ship.

To practice the fixing steps with this proposed method, the detail is illustrated in flowchart as shown in Figure 5.

\section{Numerical Example and Results}

In this section, two numerical examples were carried out to illustrate the content of the proposed approach for celestial navigation method. The gulf of Tonkin of Viet Nam was chosen 
Table 2. Result of obtaining latitude by secant method (Example 1)

\begin{tabular}{ccccc}
\hline Iterative loop & Inputs (deg) & $F$ & Solution $(\mathrm{deg})$ & Iterative error $\left(\left|\varphi_{n}-\varphi_{n-1}\right|\right)$ \\
\hline Iter1 & $\varphi_{1}=21$ & 0.00741063 & 20.629904 & 0.62990432 \\
& $\varphi_{2}=20$ & -0.01261292 & & \\
Iter2 & 20.629904 & $9.39195 \mathrm{E}-05$ & 20.625249 & 0.00465578 \\
Iter3 & 20.625249 & $1.17796 \mathrm{E}-06$ & 20.625189 & $5.9135 \mathrm{E}-05$ \\
\hline
\end{tabular}

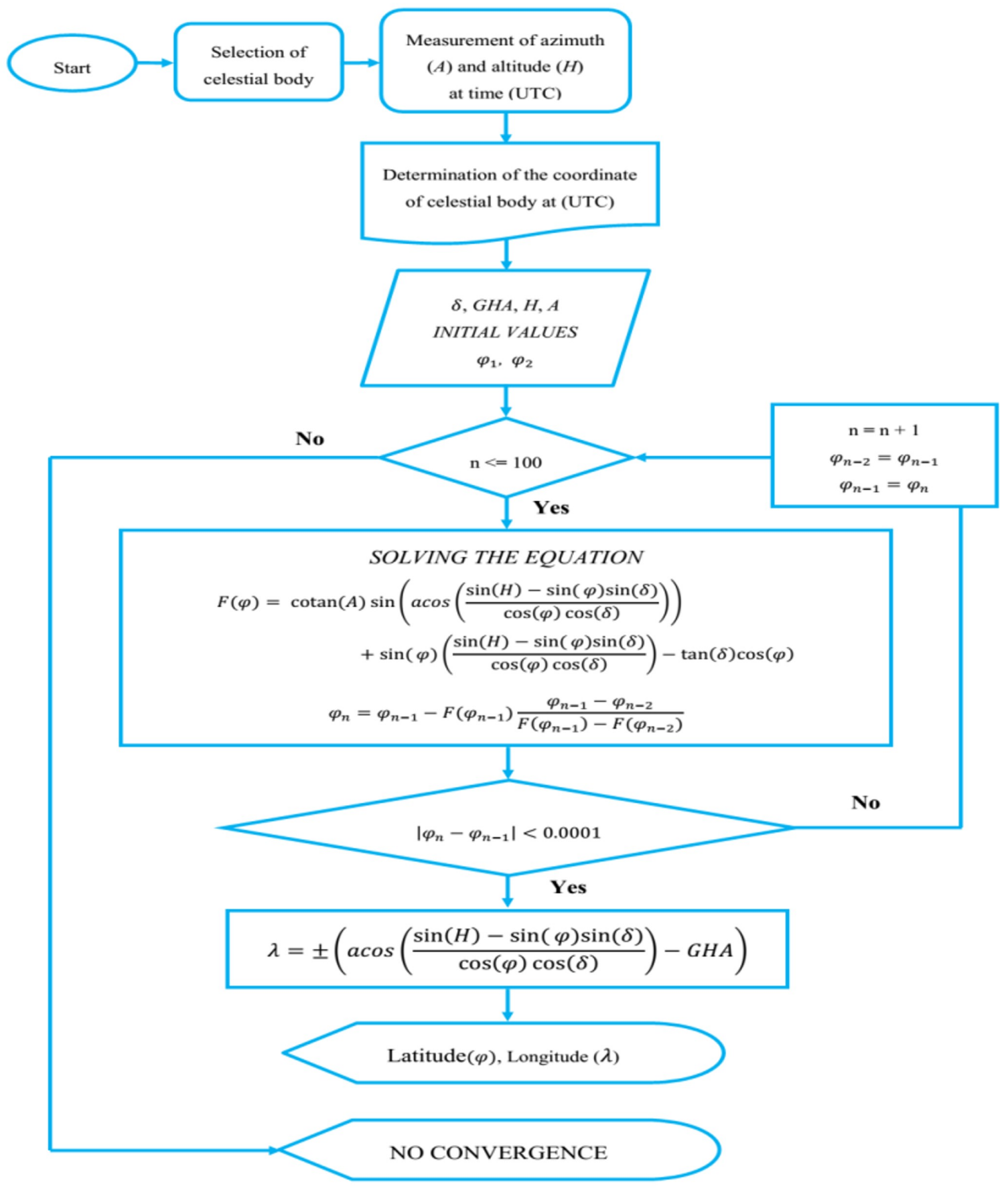

Figure 5. The flowchart of the proposed fixing method. 
Table 3. Result of obtaining latitude by secant method (Example 2)

\begin{tabular}{ccccc}
\hline Iterative loop & Inputs $(\mathrm{deg})$ & $F$ & Solution $(\mathrm{deg})$ & Iterative error $\left(\left|\varphi_{n}-\varphi_{n-1}\right|\right)$ \\
\hline Iter1 & $\varphi_{1}=21$ & 0.0235923 & 20.76205 & 0.762047 \\
& $\varphi_{2}=20$ & -0.075554 & & 0.007632 \\
Iter2 & 20.76205 & 0.0007643 & 20.75441 & 0,000254 \\
Iter3 & 20.75441 & $2.461 \mathrm{E}-05$ & 20.75416 & $8.44 \mathrm{E}-08$ \\
\hline Iter4 & 20.75416 & $-8.19 \mathrm{E}-09$ & 20.75416 & \\
\hline
\end{tabular}

to take sight the celestial body for these examples. The detail of numerical examples is shown as follows:

Example 1: On April 1, 2019, a ship travels with speed 14 knots and course $112^{\circ}$. The closest position of the ship before observing the celestial body is at $\left(20^{\circ} 44^{\prime} 6 \mathrm{~N}, 107^{\circ} 06^{\prime} 4 \mathrm{E}\right)$. The star named MIRFAK was chosen to observe the altitude and the azimuth simultaneously. The true position of ship at observation time was recorded at $\left(20^{\circ} 37^{\prime} 5 \mathrm{~N}, 107^{\circ} 16^{\prime} 3 \mathrm{E}\right)$. At time $U T C=11: 40: 07$, the altitude and the azimuth of MIRFAK were measured as $\left(H=34^{\circ} 31^{\prime} 9\right)$ and $\left(A=317^{\circ} 18\right)$.

At time $U T C=11: 40: 07$, the coordinate of MIRFAK was determined as $\left(G H A=313^{\circ} 09^{\prime} 5, \delta=49^{\circ} 55^{\prime} 7 \mathrm{~N}\right)$. Using the two initial solutions $\varphi_{1}=21^{\circ} \mathrm{N}$ and $\varphi_{2}=20^{\circ} \mathrm{N}$ for Eq. (11).

By applying Eq. (10) and Eq. (11), the equation system for the latitude was solved. The detail is shown as the following Table 2.

The solution of latitude by Secant technique was obtained after three iterations $\left(\varphi=20.62519^{\circ}=20^{\circ} 37^{\prime} 5 \mathrm{~N}\right)$.

The longitude was found based on Eq. (8), and the result of the ship position was $\varphi=20^{\circ} 37^{\prime} 5 \mathrm{~N}, \lambda=107^{\circ} 16^{\prime} 3 \mathrm{E}$. The error of the ship position was determined as 0.09 NM from the true ship position.

Example 2: On April 30, 2019, a vessel moves with speed 12.5 knots and course $120^{\circ}$. The closest position of the ship before observing the celestial body is at $\left(20^{\circ} 40^{\prime} 9 \mathrm{~N}, 107^{\circ} 12^{\prime} 8 \mathrm{E}\right)$. The star named DUBHE was chosen to observe the altitude and the azimuth simultaneously. The true position of ship at observation time was recorded at $\left(20^{\circ} 45^{\prime} 2 \mathrm{~N}, 107^{\circ} 20^{\prime} 6 \mathrm{E}\right)$. At time $U T C=10: 51: 22$, the altitude and the azimuth of DUBHE were measured as $\left(H=41^{\circ} 27^{\prime} 1\right)$ and $\left(A=22^{\circ} 93\right)$.

At time UTC $=10: 51: 22$, the coordinate of DUBHE was determined as $\left(G H A=214^{\circ} 42^{\prime} 5, \delta=61^{\circ} 39^{\prime} 1 \mathrm{~N}\right)$. Using the two initial solutions $\varphi_{1}=21^{\circ} \mathrm{N}$ and $\varphi_{2}=20^{\circ} \mathrm{N}$ for Eq. (11).

Similarly, the equation system for the latitude was solved by applying Eq. (10) and Eq. (11). The solution was obtained after four iterations: $\varphi=20.7542^{\circ}=20^{\circ} 45^{\prime} 2 \mathrm{~N}$. The detail is shown as Table 3.
The longitude was found based on Eq. (8), and the result of the ship position was $\varphi=20^{\circ} 45^{\prime} 2 \mathrm{~N}, \lambda=107^{\circ} 20^{\prime} 4 \mathrm{E}$. The error of the ship position was determined as $0.17 \mathrm{NM}$ from the true ship position.

From above-mentioned examples, it can find that the new approach is possible to apply theorically to numerical problems. In the future, this technique will be investigated with more examples and real expriments to verify it's feasibility. In addition, the external disturbances such as wind, current, and wave can be also considered for this celestial navigation technique.

\section{Conclusions}

In this study, a new approach is proposed for fixing based on a single body and secant technique to obtain the ship position. The conclusion is summarized as follows:

- First, the mathematical equations relating the ship position to celestial body were described based on an altitude and an azimuth of celestial body. These equations were established using knowledge of spherical trigonometry.

- Second, this proposed technique used both parameters which are the altitude and the azimuth of a single celestial body; therefore this technique can perform with a single celestial body at a specified time when there is only a single celestial body identified.

- Finally, applying secant technique to solve the system is seen as one of new approaches of advanced mathematics in celestial navigation. This approach can be a useful reference for navigators and marine students.

Although numerical examples were carried out by the proposed approach, some limitations were still found out in this method. One of them is a large error in observed azimuth. In the future, it is necessary to research the effect of the error in observed azimuth on the ship position. 


\section{Conflict of Interest}

No potential conflict of interest relevant to this article was reported.

\section{References}

[1] T. P. Hsu, C. L. Chen, and J. R. Chang, "New computational methods for solving problems of the astronomical vessel position," The Journal of Navigation, vol. 58, no. 2, pp. 315-335, 2005. https://doi.org/10.1017/ S0373463305003188

[2] A. R. Gonzalez, "Vector solution for the intersection of two circles of equal altitude," The Journal of Navigation, vol. 61, no. 2, pp. 355-365, 2008. https://doi.org/10.1017/ S0373463307004602

[3] M. C. Tsou, "Genetic algorithm for solving celestial navigation fix problems," Polish Maritime Research, vol. 19, no. 3, pp. 53-59, 2012. https://doi.org/10.2478/v10012012-0031-5

[4] M. C. Tsou, "Celestial navigation fix based on particle swarm optimization," Polish Maritime Research, vol. 22, no. 3, pp. 20-27, 2015. https://doi.org/10.1515/pomr-20150052

[5] V. S. Nguyen and N. Im, "Development of computer program for solving astronomical ship position based on circle of equal altitude equation and SVD-least square algorithm," Journal of Navigation and Port Research, vol. 38, no. 2, pp. 89-96, 2014. https://doi.org/10.5394/KINPR. 2014.38.2.89
[6] F. Pierros, "Stand-alone celestial navigation positioning method," The Journal of Navigation, vol. 71, no. 6, pp. 1344-1362, 2018. https://doi.org/10.1017/ S0373463318000401

[7] V. S. Nguyen, N. K. Im, and Q. D. Dao, "Azimuth method for ship position in celestial navigation," International Journal of e-Navigation and Maritime Economy, vol. 7, pp. 55-62, 2017. https://doi.org/10.1016/j.enavi.2017.06.006

[8] Z. Lusic, "Astronomical position without observed altitude of the celestial body," The Journal of Navigation, vol. 71, no. 2, pp. 454-466, 2018. https://doi.org/10.1017/ S037346331700073X

[9] V. S. Nguyen, "A novel approach to determine the ship position with an azimuth of celestial body and factors of ship route," International Journal of Civil Engineering and Technology, vol. 10, no. 2, pp. 1162-1167, 2019.

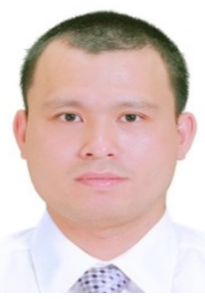

Van Suong Nguyen received his M.Sc. in Navigation Science in 2012 from Vietnam Maritime University and his Ph.D. in Maritime Safety System in 2016 from Mokpo National Maritime University, Korea. Since 2010, he has worked as a lecturer in Vietnam Maritime University. His research interests include marine navigation, ship control and automation, maritime traffic, and ocean engineering.

E-mail: nguyenvansuong@ @imaru.edu.vn 